\title{
PROTOCOLO PARA AVALIAÇÃO DA EFICÁCIA ANTI-INCRUSTANTE E PROPRIEDADES FÍSICAS DE REVESTIMENTOS APLICADOS NA SUPERFICIE INTERNA DAS GALERIAS E DO TUNEL DE DESCARGA DE ÁGUA DO MAR QUE REFRIGERA O SISTEMA DE VAPOR PRINCIPAL DA USINA NUCLEAR DE ANGRA 1
}

\author{
GOMES FILHO, S.D. \\ Engenheiro civil \\ Eletronuclear e UniFOA \\ Rio de Janeiro, Brasil \\ alfabeta123@globo.coml
}

\author{
COUTINHO, R. \\ Biólogo \\ IEAPM \\ Rio de Janeiro, Brasil \\ ricardo.coutinho@marinha.mil.br
}

\author{
GAMBARATO, B.C. \\ Engenheiro Bioquímico \\ UniFOA \\ Rio de Janeiro, Brasil \\ bruno.gambarato@foa.org.br
}

\section{RESUMO}

A usina nuclear de Angra 1 gera energia elétrica a partir da transferência de calor produzida no reator para dois geradores de vapor que acionam um turbogerador. O vapor gerado condensa em contato com a superfície externa de feixes tubulares do condensador, onde circula internamente a água do mar que é captada pelo túnel de admissão e descarregada através de um túnel de concreto armado onde gera bioincrustação, aumento da rugosidade e impede a inspeção dessa estrutura. O objetivo da pesquisa foi avaliar a atividade da bioincrustação, a eficácia anti-incrustante, formação de bolhas e aderência de revestimentos MC-DUR 2496 CTP do fornecedor MC-Bauchemie; PLASTEEL AZUL PINTÁVEL, PLASTEEL ANTI CRACA e PLASTEEL ALTA RESISTÊNCIA QUÍMICA do fornecedor QUIMATIC/TAPIMATIC; ICOSIT K 101 TW do fornecedor SIKA e INTERSLEEK 1100 SR do fornecedor AKZO NOBEL. Foram selecionadas seis áreas para remoção e classificação taxonômica da bioincrustação e aplicação dos revestimentos donde se concluiu que a bioincrustação está ativa e que os revestimentos PLASTEEL AZUL PINTÁVEL, ICOSIT K 101 TW e PLASTEEL ANTI CRACA se mantiveram aderidos à superfície interna do túnel apesar de não testados contra a bioincrustação em vista de baixa velocidade de desenvolvimento da craca da espécie Megabalanus coccopoma. Os revestimentos MC-DUR 2496 CTP e INTERSLEEK 1100 SR tiveram seus desempenhos comprometidos por formação de bolhas e delaminação enquanto o revestimento PLASTEEL ALTA RESISTÊNCIA QUÍMICA foi totalmente encoberto pelo molusco gastrópode Petaloconchus varians da família Vermetidae.

Palavras-chave: concreto armado,bioincrustação, anti-incrustante.

\section{ABSTRACT}

The Angra 1 nuclear power plant generates electricity from the heat transfer produced in the reactor to two steam generators that activate a turbogenerator. The steam generated condenses in contact with the outer surface of tubular beams of the condenser, where seawater circulates internally, which is captured by the intake tunnel and discharged through a reinforced concrete tunnel where it generates bio-encrustation, increased roughness and prevents inspection. of that structure. The objective of the research was to evaluate the activity of bio-encrustation, the anti-fouling efficacy, bubble formation and adhesion of coatings MC-DUR 2496 CTP from the supplier MC-Bauchemie; PAINTABLE BLUE PLASTEEL, PLASTEEL ANTI CRACA and PLASTEEL HIGH CHEMICAL RESISTANCE from the supplier QUIMATIC / TAPIMATIC; ICOSIT K 101 TW from supplier SIKA and INTERSLEEK 1100 SR from supplier AKZO NOBEL. Six areas were selected for removal and taxonomic classification of bio-encrustation and application of coatings, where it was concluded that bio-encrustation is active and that PLASTEEL AZUL PAINTABLE, ICOSIT K 101 TW and PLASTEEL ANTI CRACA coatings remained adhered to the internal surface of the tunnel although not tested against bio-encrustation in view of the low development speed of the barnacle of the Megabalanus coccopoma species. The coatings MC-DUR 2496 CTP and INTERSLEEK 1100 SR had their performance compromised by bubble formation and delamination while the PLASTEEL HIGH RESISTANCE CHEMICAL coating was completely covered by the gastropod mollusc Petaloconchus varians of the Vermetidae family.

Keywords: reinforced concrete, bio-encrustation, anti-fouling. 


\section{PROBLEMA}

Após troca de calor com o vapor que rodou as turbinas onde promove a sua condensação deste vapor, a água do mar é descarregada na praia Piraquara de Fora (ELETRONUCLEAR, 2004) através do túnel de descarga onde gera bioincrustação que além de aumentar a rugosidade da superfície interna (Safriel et al., 1993), impede a inspeção das estruturas de concreto na região de maior crescimento (Figura 1).

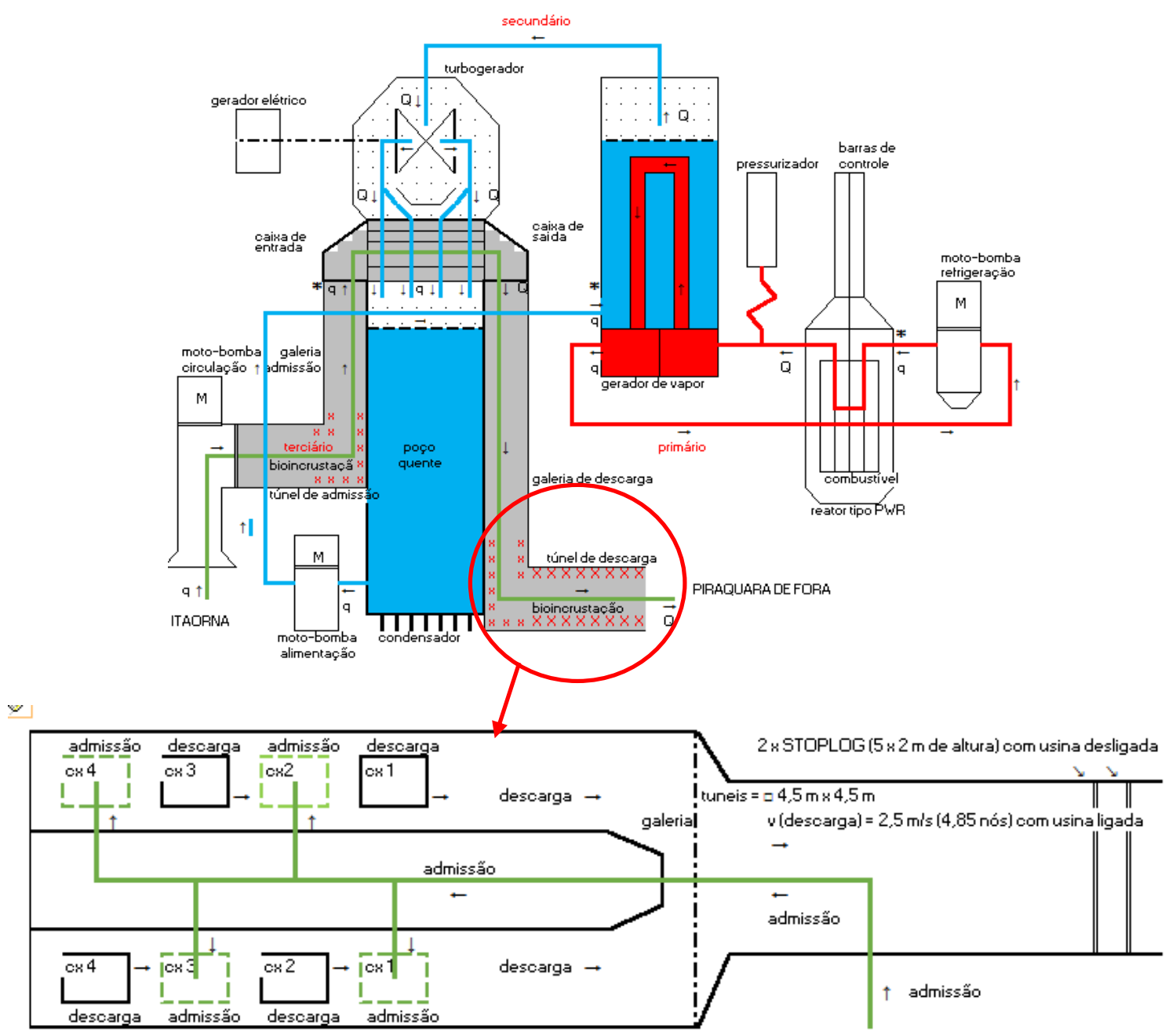

Figura 1: Esquema do processo de geração de energia com destaque para a área de crescimento da bioincrustação Fonte: Fonte: GOMES FILHO, SD

A bioincrustação formada na superfície interna das galerias e do túnel de descarga da mesma maneira que se formava no túnel e galerias de admissão (LEITE, 1999), impede a inspeção das estruturas de concreto armado do túnel, impossibilitando a detecção de manifestações patológicas e a intervenção precoce para evitar a ocorrência de anomalias na estrutura de concreto do túnel. Dentre as manifestações patológicas mais relevantes destacamos as fissuras pelas quais entram vapores de cloretos e sulfatos na estrutura de concreto do túnel de descarga. Dentre as anomalias mais relevantes, destacamos a despassivação e a corrosão da armadura (Helene, 1993), formação e expansão de produtos de corrosão e desplacamentos provocados pela entrada de cloretos e sulfatos da água do mar por fissuras na estrutura de concreto armado do túnel de descarga.

Foram encontradas, nas inspeções visuais realizadas na estrutura de concreto armado da superfície interna da do túnel em 2016, 2017 e 2018, carapaças de bioincrustação onde não se observou forte cheiro de gás sulfídrico resultante de decomposição da bioincrustação gerando a suspeita sobre a sua atividade. Feitas a inspeção visual da superfície interna do túnel, classificação taxonômica da bioincrustação e a aplicação dos revestimentos, torna-se necessário saber se a bioincrustação está ativa ou inativa e qual a revestimento que além das melhores propriedades físicas, apresenta maior 
eficácia contra a fixação da bioincrustação na superfície interna do túnel para subsidiar decisão da alta administração da usina sobre a abrangência da real necessidade ou não da aplicação dos revestimentos ora discutidos.

\section{HIPÓTESES}

\subsection{Bioincrustação ativa}

A aplicação de revestimento que apresenta as melhores propriedades físicas e mecânicas e a maior eficácia contra a fixação da bioincrustação é necessária pois a fixação da bioincrustação na superfície interna do túnel está ativa e continuará impedindo a inspeção visual da superfície interna do túnel e a visualização de manifestações patológicas e eventuais anomalias em razão do crescimento da bioincrustação, prejudicando a manutenção preventiva da estruturas de concreto armado dos túneis.

\subsection{Bioincrustação Inativa}

Não foi possível identificar a revestimento que apresenta as melhores propriedades físicas e mecânicas e a maior eficácia contra a fixação da bioincrustação porque a bioincrustação está inativa e aplicação de revestimento não é necessária; basta a remoção das carapaças da bioincrustação presente na superfície interna das paredes de concreto armado do túnel pois estas carapaças são remanescentes anterior à injeção do biocida hipoclorito de sódio, atualmente instalada, que inibe a fixação da bioincrustação nas paredes do túnel.

\section{JUSTIFICATIVA E OBJETIVO}

Por ocasião de um curso da norma ABNT NBR 16230 de 2013, que trata de inspeção de estruturas de concreto, um dos instrutores o Prof. Dr. Paulo Helene comentou, em resposta a uma observação do autor sobre a bioincrustação nas paredes internas do túnel que, no seu entendimento, a bioincrustação deveria proteger a estrutura das paredes em razão da sua carapaça de calcário. Ele acrescentou, ainda, que para executar a inspeção de uma estrutura de concreto é necessário que a sua superfície esteja nua o que remeteu à necessidade de remover a bioincrustação da superfície interna do túnel.

Como o túnel fica inundado durante a operação, somente é possível inspeciona-lo em paradas da usina para recarregamento do núcleo do reator, quando ele é drenado e numa inspeção da estrutura de concreto do túnel de admissão executada em 2016, posterior ao curso de inspeção de estruturas de concreto, classificamos como "suspeita" de degradação uma área da superfície interna deste túnel que estava coberta por bioincrustação. Na parada posterior, em 2017, a suspeita se confirmou donde concluí que aquela bioincrustação havia impedido a inspeção correta da estrutura do túnel o que resultou que uma manifestação patológica (fissura) não foi detectada a tempo de evitar um princípio de anomalia (corrosão de armadura da estrutura do concreto da estrutura detectada mediante produtos de corrosão no piso e na laje de cobertura do túnel de admissão. A recuperação da estrutura não foi possível em 2017 em razão do retorno da usina à operação quando o túnel é inundado. Posteriormente, em 2020, procedemos a recuperação da estrutura mediante injeção de poliuretano, abertura de janela de inspeção na estrutura, avaliação de armadura onde foi verificado que não havia perda de sessão. Posto isto, foi aplicado produto anticorrosivo na armadura e fechada a janela de inspeção com graute.

Uma das formas de evitar a entrada de cloretos e sulfatos pelas fissuras, detectar a ocorrência das mesmas e evitar a fixação da bioincrustação sobre a superfície interna do túnel é a aplicação de revestimento que além de impedir a entrada dos contaminantes, poderia impedir ou dificultar a fixação da bioincrustação na superfície do túnel, possibilitando a detecção precoce de manifestações patológicas em inspeções periódicas. Surge daí a necessidade da aplicação de revestimento para proteção da superfície interna do túnel que consiga: 1. Impedir a entrada de cloretos da água do mar que poderiam penetrar por fissuras e provocar corrosão da armadura e 2. Inibir a fixação da larva de cracas e moluscos e desenvolvimento de bioincrustação, tornando possível a inspeção da estrutura do túnel. A inspeção periódica da estrutura civil do túnel possibilita detectar manifestações patológicas no seu início e previne a ocorrência de anomalias em estado mais avançado, o que pode resultar em: 1. Aumento do tempo de usina desligada em razão da necessidade de manter o túnel drenado para executar recuperação da sua estrutura atacada por anomalia; 2. Indisponibilidade da energia produzida para o sistema elétrico nacional o que provoca perda de faturamento para a Eletronuclear que é a empresa operadora da usina nuclear de angra 1; 3. Redução da confiança da sociedade na produção de energia elétrica por usinas nucleares em razão da falta de energia, ainda que temporária, para suprir a necessidade da sociedade civil no seu cotidiano. 
O objetivo desta pesquisa é avaliar o desenvolvimento da bioincrustação, as propriedades físicas mediante os ensaios de formação de bolhas e teste de aderências nos revestimentos bem como a eficácia anti-incrustantes dos revestimentos aplicados na superfície interna do túnel de água do mar que refrigera o sistema de vapor principal da usina nuclear de Angra I.

\section{METODOLOGIA}

Trata-se de PESQUISA APLICADA, quanto à finalidade, pois este manuscrito trata de estudo aplicado à estrutura de concreto armado do túnel de descarga da usina nuclear de angra 1. Trata-se de PESQUISA EXPLORATÓRIA, quanto ao objetivo, pois buscou-se identificar, numa primeira inspeção, a identificação de problemas existentes na estrutura do túnel onde foi verificada a bioincrustação na superfície interna do mesmo. Trata-se, também, de PESQUISA DESCRITIVA, quanto ao objetivo, pois numa segunda inspeção foram executados registros fotográficos da bioincrustação e a classificação taxonômica da bioincrustação. Trata-se, ainda, de PESQUISA EXPLICATIVA, quanto ao objetivo, pois busca verificar se a bioincrustação está ativa e avaliar a eficácia anti-incrustante das revestimento que foram aplicadas na superfície interna do túnel de descarga. Trrata-se de PESQUISA QUALI-QUANTITATIVA, quanto à abordagem, pois o desenvolvimento da bioincrustação e a eficácia anti-incrustante dos revestimentos serão avaliados mediante registro de medições da bioincrustação, ensaios físicos dos revestimentos aplicadas e análise valorativa do pesquisador. Trata-se de PESQUISA HIPOTÉTICO-DEDUTIVA, quanto ao método, pois busca verificar quais das hipóteses sobre a atividade da bioincrustação se confirma e qual dos revestimentos se mostrará mais eficaz contra o desenvolvimento de bioincrustação se ativa e contra o ataque por cloreto contido na água do mar sobre a estrutura da superfície interna do túnel. Trata-se de PESQUISA BIBLIOGRÁFICA, DOCUMENTAL e ESTUDO DE CASO, quanto ao procedimento, pois a partir de trabalhos científicos e documentos estabelece as hipóteses que serão objeto de confirmação (Gil, 2002).

\section{ETAPAS DA PESQUISA}

\subsection{Seleção de 6 áreas na região de maior crescimento e remoção da bioincrustação na superfície interna do túnel de descarga}

Foram selecionadas, em setembro de 2017, 4 áreas na região de maior crescimento da bioincrustação no início do túnel de descarga para remoção desta bioincrustação e aplicação de revestimentos de fornederores participantes da pesquisa. Foi selecionada, em outubro de 2018, uma quinta área na região de maior crescimento da bioincrustação da parede divisória das galerias de descarga e uma sexta área na região de maior crescimento da bioincrustação na metade do túnel de descarga para remoção da bioincrustação e aplicação de revestimento e verificação de sua eficácia anti-incrustante (Figura 2). Foi removida a bioincrustação, em setembro de 2017 e outubro de 2018, em 6 quadros de 3 x $3 \mathrm{~m}$ com hidrojato a pressão de 27.000 psi a 45 graus com a superfície (Figura 2). Posteriormente, foram removidos os resíduos da fixação da bioincrustação mediante limpeza com formão e preparada com utilização de lixadeira.
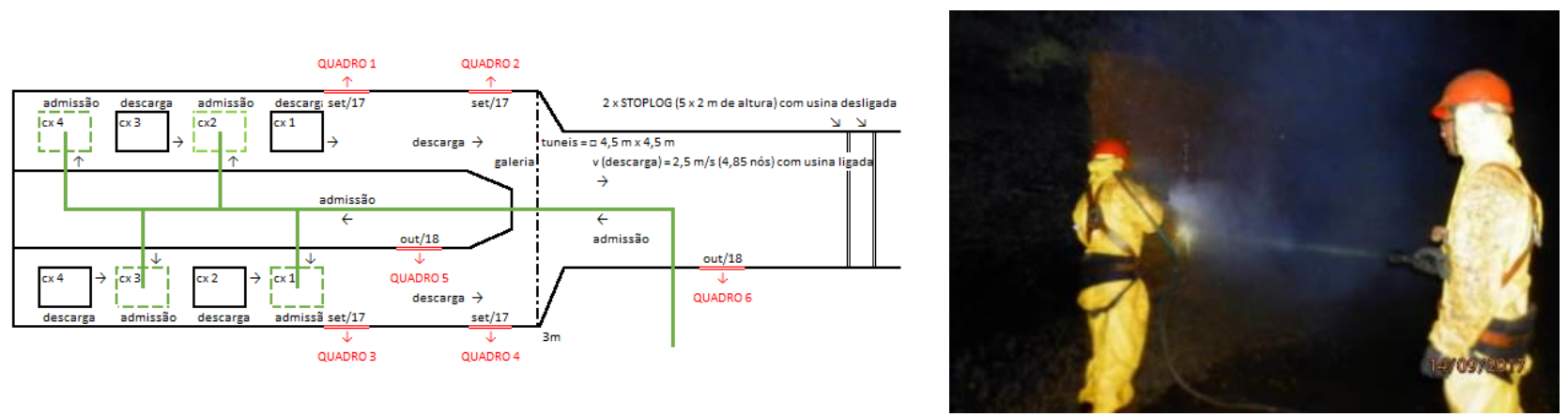

Figura 2: Seleção de seis áreas da remoção da bioincrustação em seis quadros de 3 x 3m Fonte: GOMES FILHO, SD

\subsection{Classificação taxonômica da bioincrustação}

Foi coletada amostra da bioincrustação na região de maior crescimento em outubro de 2018 de maneira que esta amostra contivesse representantes de todas as espécies observadas em toda a superfície interna do túnel de descarga. 
Concluida a amostra, esta foi encaminhada ao laboratório de monitoração ambiental - LMA da Eletronuclear para classificação taxonômica da bioincrustação. Como resultado da classificaçãoda Eletronuclear feita pelo Laboratório de Monitoração Ambiental - LMA, foram encontradas craca da espécie Megabalanus coccopoma e o molusco gastrópode Petaloconchus varians da família Vermetida (Figura 3).
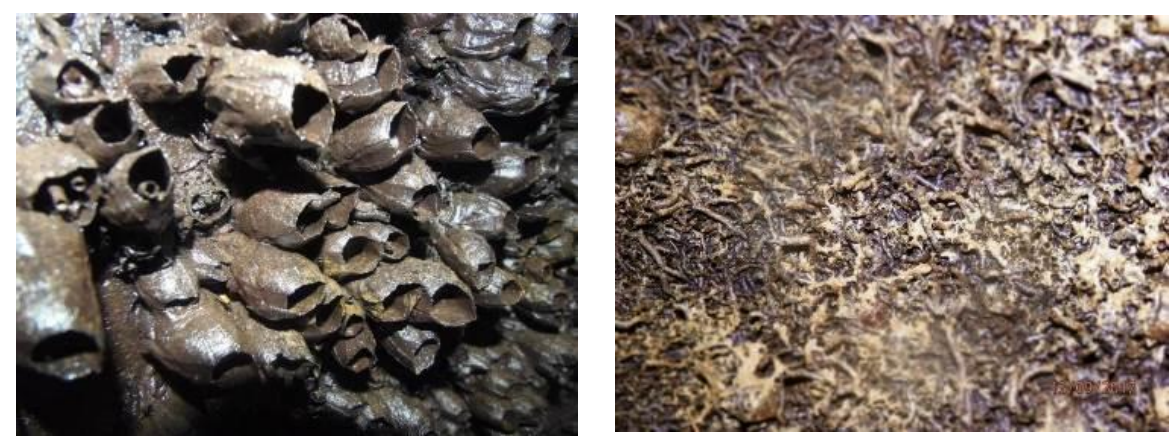

Figura 3: Craca da espécie Megabalanus coccopoma e do molusco gastrópode Petaloconchus varians da família Vermetidae presentes na superfície interna das galerias e do túnel de descarga, respectivamente Fonte: GOMES FILHO, SD

\subsection{Aplicação das amostras de 6 revestimentos em 5 quadros na superfície interna do túnel de descarga em} setembro de 2017 e outubro de 2018.

Após o hidrojateamento e limpeza com formção, as superfícies dos seis quadros de 3 x $3 \mathrm{~m}$ na superfície interna do início do túnel de descarga foram preparadas com utilização de lixadeira e lavagem com hidrojato à baixa pressão em setembro de 2017 e outubro de 2018. Após a preparação foram aplicadas, em setembro de 2017, os 5 revestimentos MC-DUR 2496 CTP do fornecedor MC-Bauchemie Brasil (revestimento 1); PLASTEEL AZUL PINTÁVEL do fornecedor QUIMATIC/TAPIMATIC (revestimento 2); revestimento ICOSIT K 101 TW do fornecedor SIKA Brasil (revestimento 3); revestimento INTERSLEEK 1100 SR do fornecedor AKZO NOBEL (revestimento 4) e revestimento PLASTEEL ANTI CRACA do fornecedor QUIAMTIC TAPIMATIC (revestimento 5) nos 4 quadros de 3 x $3 \mathrm{~m}$ na superfície interna do início do túnel de descarga em subáreas de 0,60m x 1,5m com utilização de rolo (Figura 4). Foi aplicada, em outubro de 2018, a revestimento PLASTEEL CERÂMICO ALTA RESISTÊNCIA QUÍMICA do fornecedor QIMATIC TAPIMATIC (revestimento 6) na superfície interna da metade do túnel de descarga em subárea de 1,00 x 1,5m com utilização pincel (Figura 4). Optou-se, para efeito de avaliação do desenvolvimento da bioincrustação por deixar um quadro de $3 \times 3 \mathrm{~m}$ superfície interna da parede divisória das galerias de descarga sem nehum revestimento.

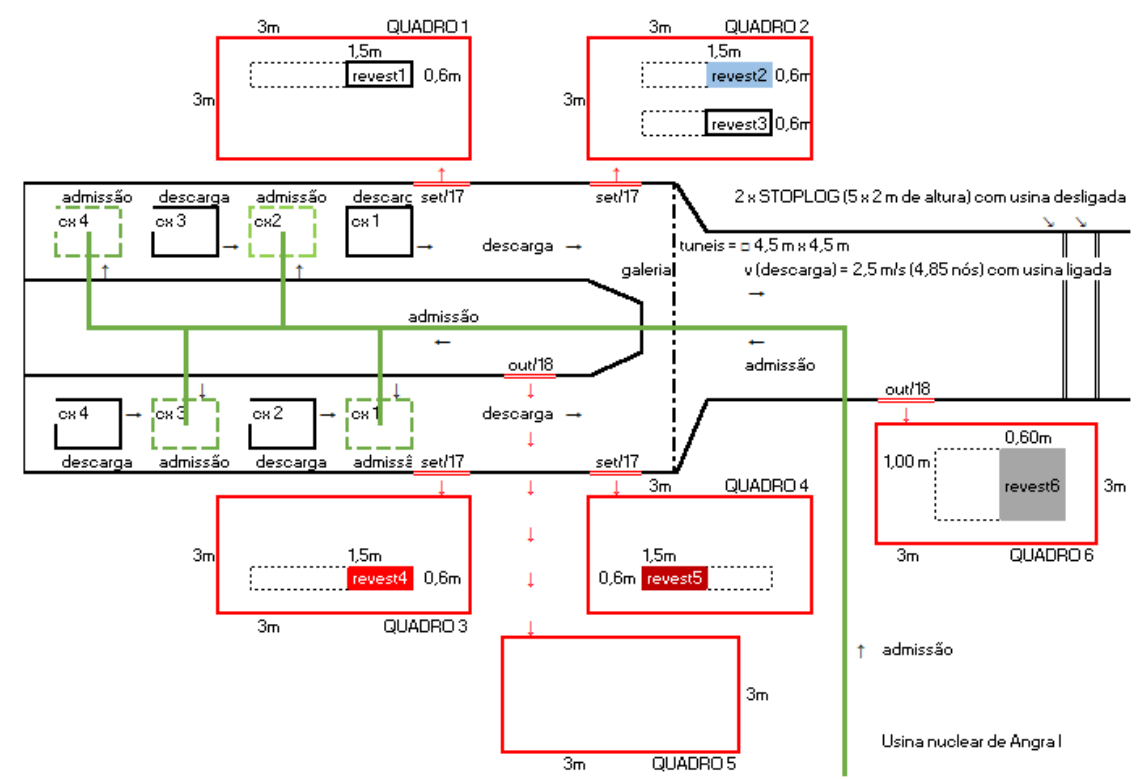

Figura 4: Esquema de aplicação dos revestimentos na superfície interna do túnel de descarga Fonte: GOMES FILHO, S D 


\section{RESULTADOS}

Para avaliação das propriedades físicas dos revestimentos aplicadas foram eleitos os parâmetros 1) ENSAIO DE ADERÊNCIA descrito na norma técnica ASTM D7234-12 - Método de Teste para Resistência à Adesão de Pull-Off de revestimentos no concreto usando testadores de adesão de remoção portátil e 2) FORMAÇÃO DE BOLHAS descrito na norma técnica ASTM D714-02 - Método de Teste para Avaliar o Grau de Formação de Bolhas de Revestimentos.

6.1 Avaliação [1] do desenvolvimento da bioincrustação nos 6 quadros de 3 x $3 \mathrm{~m}$ da superfície interna das galerias e do túnel de descarga com e sem revestimento aplicada e da eficácia anti-incrustante das 6 revestimentos aplicadas nos 5 quadros da superfície interna do túnel de descarga 1 ano e 2 anos e 3 meses após aplicação.

Para avaliação do desenvolvimento da bioincrustação em janeiro de 2020 foi construido dispositivo denominado "frame" (Figura 5) para fixação da camêra fotográfica visando garantir a mesma distância da máquina até a superfície do túnel para todas as fotos e tornar mais prático e rápido o registro fotográfico padronizado visto que a vestimenta utilizada no túnel (TYVEC) restringia a respiração da pele e a ventilação do corpo o que causava excessiva transpiração.

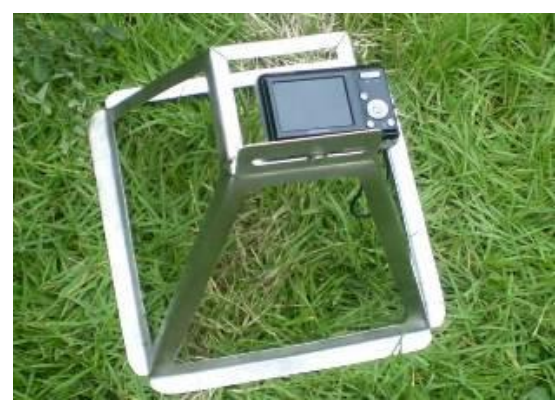

Figura 5: Frame construído em chapa de aço inox para fixação da câmera fotográfica para padronização das fotos Fonte: GOMES FILHO, S D

$\mathrm{Na}$ avaliação da atividade da bioincrustação, foi observado que no quadro one não foi aplicada nenhuma revestimento houve crescimento tanto da craca da espécie Megabalanus coccopoma quanto do molusco gastrópode Petaloconchus varians da família Vermetida com destaque para o grande crescimento do molusco em relação à craca o que sugere que em regiões de maior velocidade da água no túnel prevalece o crescimento do molusco.

Contrário sensu, confirmando a situação encontrada em 2017 quando da primeira inspeção do início da pesquisa, observou-se a predominância do desenvolvimento da craca nas regiões curvas ou de menor velocidade da água, em relação ao molusco. Prova disso é que, nas paredes das galerias onde foram aplicadas os revestimentos, observamos, em 2020, apenas o início do crescimento da bioincrustação.

Verificou-se que enquanto a craca, na sua região de sugerida dominância (paredes externas das galerias), esta se desenvolveu numa velocidade muito menor que o molusco tanto na parede interna da galeria quanto na região reta do túnel de descarga. Prova disso é que no quadro do túnel onde foi aplicada a revestimento PLASTEEL ALTA RESISTÊNCIA QUÍMICA o molusco, no período de outubro de 2018 a janeiro de 2020, encobriu completamente a superfície da região onde esta revestimento foi aplicada.

O desenvolvimento tanto da craca em menor velocidade quanto o desenvolvimento do molusco em maior velocidade, confirmaram a hipótese 2.1 donde concluímos que a bioincrustação está ativa.

\subsection{Ensaio de aderência (pull-off) dos revestimentos aplicados}

O ensaio de aderência também denominado pull-off consiste em colar, sobre a superfície que se quer testar, uma peça denominada "dolly" que após $24 \mathrm{~h}$ de cura da cola utiliza-se um instrumento pneumático que aplica um esforço da tração para arrancamento do dolly colado sobre a superfície indicando, num visor digital, o valor da tensão de aderência na unidade Mpa. Salientando que antes da colagem do dolly sobre a superfície da revestimento, esta deve se limpa e lixada para garantir a poefeita colagem do dolly sobre a superfície da revestimento. Após a preparação da superfície conforme 
descrito acima, foram colados três dolly segundo uma diagonal ascendente em cada uma das áreas da superfície interna das galerias e túnel de descarga onde foram aplicadas as amostras dos revestimentos. Apesar de respeitadas todas as recomendações da norma para o teste de aderência, não foi possível mensurar o valor exato da aderência dos revestimentos aplicadas na superfície das galerias em razão das condições de umidade que não possibilitaram a perfeita colagem dos dolly sobre a superfície. Ainda assim, foi possível realizar medição de aderência até o rompimento que ocorreu na cola onde obtivemos os valores de 0,18;0,30 e 0,12 MPa de aderência da cola aplicadas sobre os revestimentos PLASTEEL AZUL PINTÁVEL, ICOSIT K 101 TW e PLASTEEL ANTI CRACA, respectivamente, donde deduzimos que a tensão de aderência da revestimento no substrato é maior que os valores de tesão obtidos na aderência da cola nos revestimentos. Quanto aos revestimentos MC-DUR 2496 CTP, INTERSLEEK 1100 SR e PLASTEEL ALTA RESISTÊNCIA QUÍMICA, não foi possível a avaliação da aderência em razão de formação de bolhas densa, delaminação e encobrimento pela bioincrustação, respectivamente.

\subsection{Ensaio de formação de bolhas e inspeção visual de patologias}

Quanto ao ensaio de formação de bolhas que consiste na comparação da formação de bolhas de um padrão descrito na norma ASTM D714-02 com a formação de bolhas na pintura em proceso de avaliação, foi utilizado o mesmo dispositivo denominado "frame" (Figura 5) para fixação da camêra fotográfica pelas mesmas razões já descrito na avaliação do desenvolvimento da bioincrustação. Para a inspeção realizada em outubro de 2018, 1 ano após a aplicação dos revestimentos foi feita limpeza da superfície com jato d’água de baixa pressão antes da inspeção visual. Já em janeiro de 2020 não foi feita a mesma limpeza, sendo mantido o biofilme encontrado sobre a revestimento como tentativa de não interferir no crescimento da bioincrustação visando a continuidade do monitoramento do desenvolvimento da bioincrustação. A seguir passamos a discutir os resultados da inspeção visual e do ensaio de formação de bolhas dos seis revestimentos que foram aplicadas nos 5 quadors de 3 x $3 \mathrm{~m}$ na superfície interna da galeria e do túnel de descarga (Figura 4).

\subsubsection{Revestimento MC-DUR 2496 CTP do fornecedor MC-Bauchemie Brasil aplicado em setembro de 2017}

Poliuretano modificado de alta resistência química e mecânica, MC-DUR 2496 CTP foi aplicado em demãos cruzadas sobre o primer MC-DUR 1200 VK que apresenta os dados técnicos a seguir. Proporção de mistura em peso 100:55 base (A): endurecedor (B); Densidade 1,35 g/cm3; Viscosidade aprox. $900 \mathrm{MPa}$; Tempo de trabalhabilidade aprox. 120 minutos; Tempo de cura min. 2 horas; Tempo ate resistência total 12 horas; Condições de aplicação temperatura do ar ${ }^{\circ} \mathrm{C} \geq 2$; $\leq 35$, material e substrato, ponto de orvalho não deve estar em declínio; Consumo (por demão) aprox. 200 $300 \mathrm{~g} / \mathrm{m} 2=$ aprox. $130-200 \mu \mathrm{m}$ de espessura de camada seca

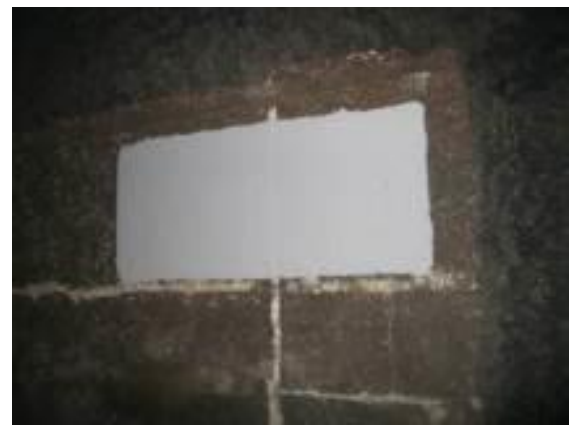

Setembro de 2017: após aplicação

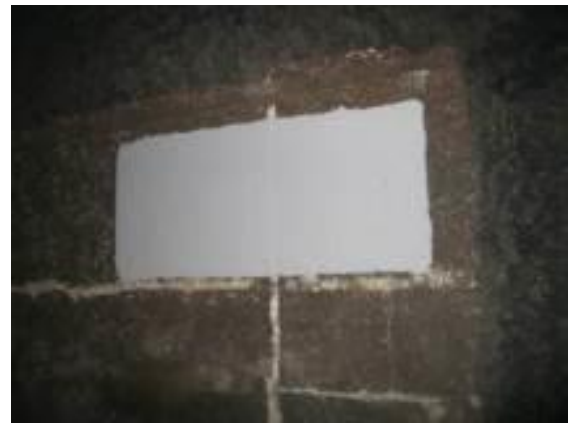

Outubro de 2018: 1 ano após aplicação

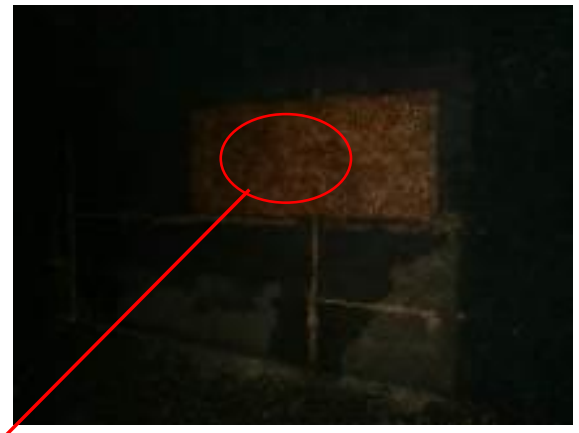

Janeiro de 2020: 2 anos e três meses após aplicação

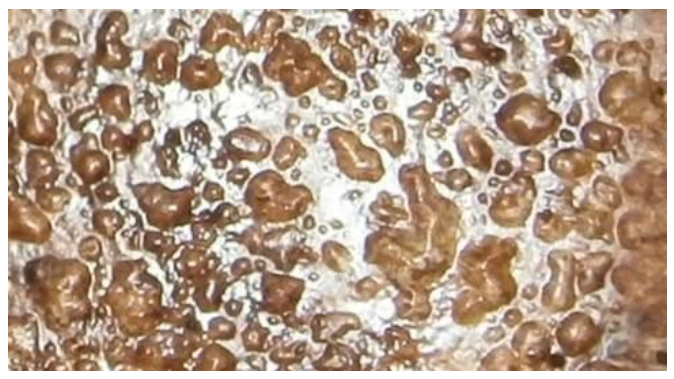

Figura 6: Revestimento MC-DUR 2496 CTP com biofilme e formação de bolhas densa e generalizada 


\author{
Fonte: GOMES FILHO, S D
}

Quanto à formação de bolhas, observou-se formação de bolhas classificada como "densa" de acordo com o padrão da norma ASTM D714-02 (Figura 6) em toda a área pintada. Observa-se que este revestimento foi sugerida pelo fornecedor para aplicação direta sobre o substrato concreto, não sendo aplicado nenhum material que pudesse funcionar como uma barreira de vapor o que pode ser uma das causas da formação de bolhas no revestimento.

6.3.2 Revestimento PLASTEEL AZUL PINTÁVEL do fornecedor QUIMATIC/TAPIMATIC aplicado em setembro de 2017

PLASTEEL AZUL PINTÁVEL é um revestimento cerâmico bi-componente, na cor azul, que proporcionando uma película lisa, com alto brilho e com baixo atrito que apresenta as propriedades (típicas para o produto curado por 7 dias a $25^{\circ} \mathrm{C}$ ) a seguir. Cor: Azul; Aspecto do produto: Sólido rígido vitrificado; Tempo máximo para aplicação a $25^{\circ} \mathrm{C}: 20$ minutos para 5,28Kg; Contração (ASTM D-2566): 0,0004-0,0006 cm; Resistência à compressão (ASTM D-695): 5,5 - 6,0 kgf/mm2; Resistência à tração (ASTM D-638): 2,3 - 2,8 kgf/mm2; Dureza Shore D (ASTM D-2240): 79 - 83; Módulo de elasticidade (ASTM D-638): 400 - $440 \mathrm{kgf} / \mathrm{mm} 2$; Coeficiente de expansão térmica (ASTM D-696): (40 46) x 10-6 cm/cm. ${ }^{\circ} \mathrm{C}$; Condutividade térmica (ASTM C-177): $(1,34-1,45) \times 10-3 \mathrm{cal} . \mathrm{cm} / \mathrm{s} . \mathrm{cm} 2 .{ }^{\circ} \mathrm{C}$; Abrasão Taber rebolo H22, 1000 ciclos (ASTM D-4060): $\leq 0,70 \mathrm{~g}$; Resistência à temperatura Contínua: $90^{\circ} \mathrm{C}$, Pico: $120^{\circ} \mathrm{C}$

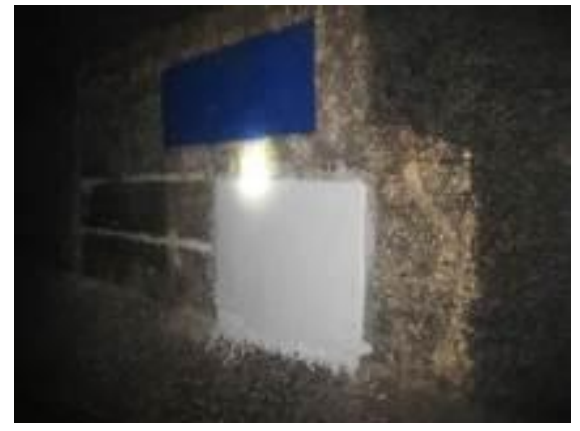

Setembro de 2017: após aplicação

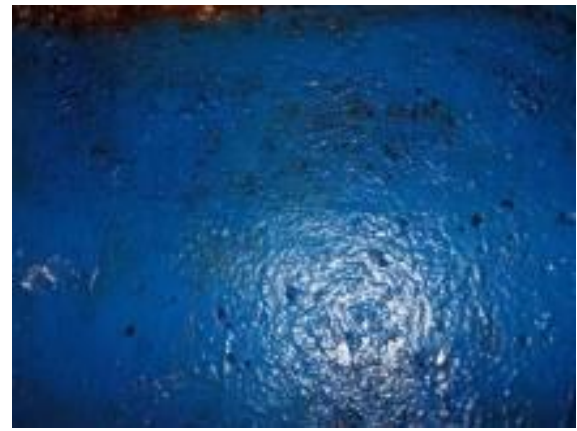

Outubro de 2018: 1 ano após aplicação

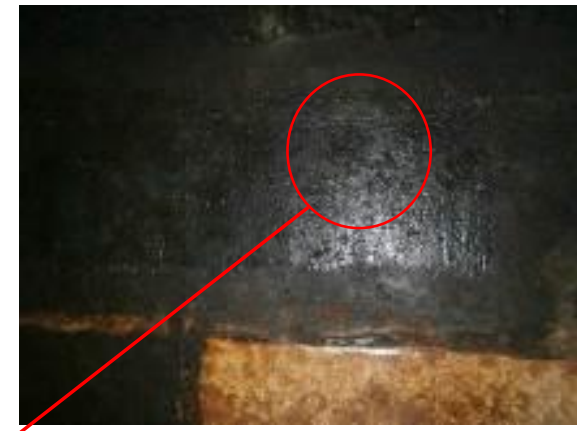

Janeiro de 2020: 2 anos e três meses após aplicação

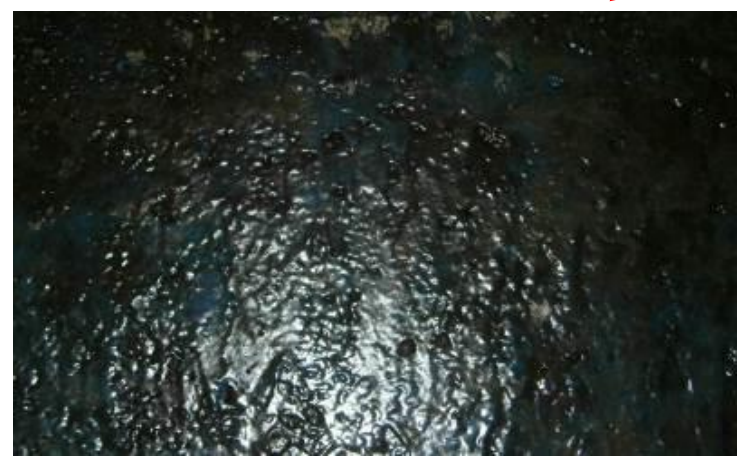

Figura 7: Revestimento PLASTEEL AZUL PINTÁVEL com destaque para o biofilme e escoamento Fonte: GOMES FILHO, S D

Não foi observada formação de bolhas de acordo com o padrão da norma ASTM D714-02. Foi, no entando observado escoamento do revestimento, ao que o fornecedor atribuiu à espessura aplicada (Figura 7).

\title{
6.3.3 Revestimento ICOSIT K 101 TW do fornecedor SIKA Brasil aplicado em setembro de 2017
}

ICOSIT K 101 TW é um é um revestimento à base de resinas de epóxi, isento de solventes, aplicado sobre o revestimento epóxi-cimento para nivelamento e barreira temporária ao vapor Sikagard 720 Epocem que apresenta os

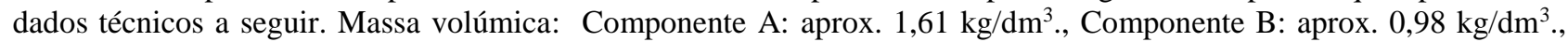
Mistura (A+B): aprox. 1,42 kg/dm 3 ; Propriedades físicas - Mecânicas; Resistência ao arrancamento: Aprox. 3 N/mm2 aos 28 dias (ruptura coesiva no concreto).; Consumo/ Dosagem Aprox. 0,35 - 0,4 kg/m2/camada, dependendo das características da base; Temperatura da base Mínima: $+10^{\circ} \mathrm{C}$.; Temperatura ambiente Mínima: $+10^{\circ} \mathrm{C}$; Ponto de 
orvalho A temperatura da base deve estar no mínimo $3{ }^{\circ} \mathrm{C}$ acima do ponto de orvalho, para reduzir o risco de condensação ou formação de bolhas no revestimento final; Relação de mistura Componente A : componente $\mathrm{B}=79: 21$ (partes em peso); Tempo de vida útil da mistura (potlife): $+10^{\circ} \mathrm{C}$ : Aprox. 45 minutos $+20^{\circ} \mathrm{C}$ :Aprox. 35 minutos; +25 ${ }^{\circ} \mathrm{C}$ : Aprox. 15 minutos

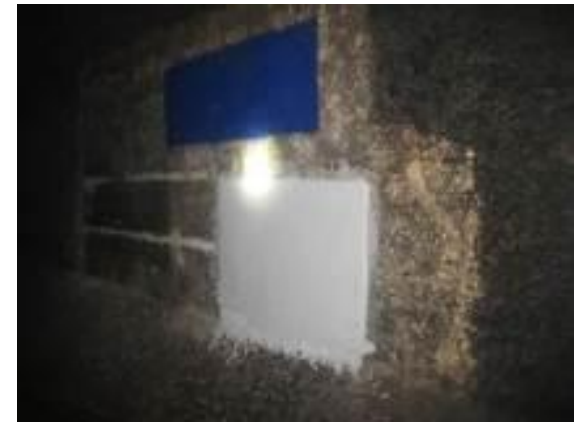

Setembro de 2017: após aplicação

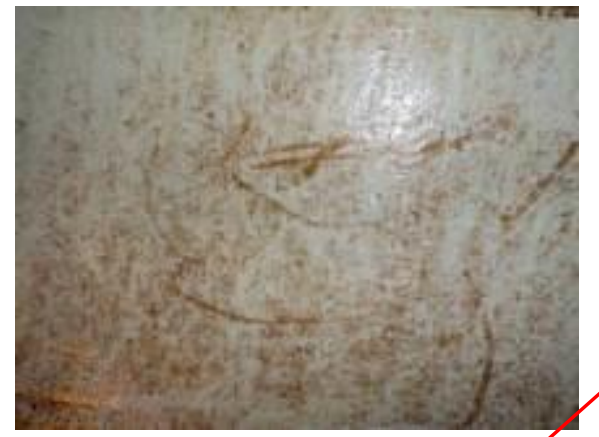

Outubro de 2018: 1 ano após aplicaç̃̃o

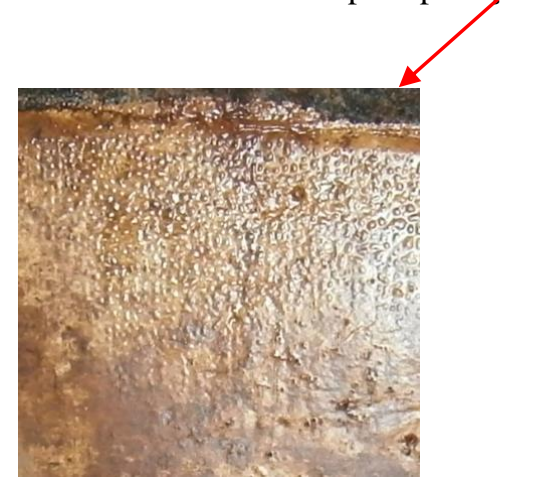

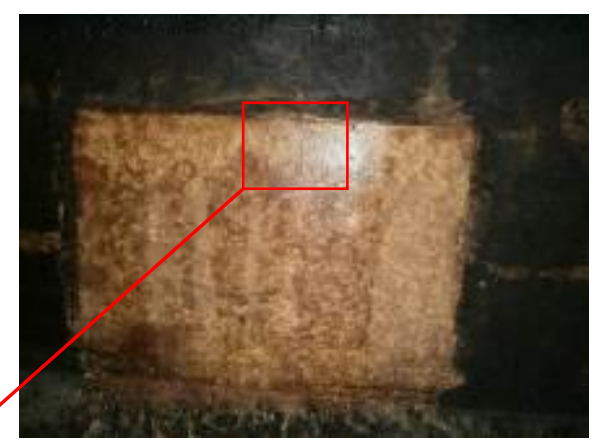

Janeiro de 2020: 2 anos e três meses após aplicação

Figura 8: Revestimento ICOSIT K 101 TW com destaque biofilme e formação de bolhas densa na parte superior Fonte: GOMES FILHO, S D

Quanto à formação de bolhas, foi observada formação localizada de bolhas classificada como densa de acordo com o padrão da norma ASTM D714-02 (Figura 8) o que poderia ser atribuido à uma falha no processo de aplicação visto que o restante da área pintada não apresentou formação de bolhas. Antes da aplicação deste revestimento, o fornecedor optou pela aplicação de argamassa polimérica para cumpriri a função de barreira de vapor para evitar a formação de bolhas segundo declaração do próprio fornecedor.

Na inspeção feita em outubro de 2018 foi observado que o revestimento ICOSIT K 101 TW do fornecedor SIKA Brasil apresentou rugosidade ao toque manual, como um alerta para o desenvolvimento de bioincrustação sobre a mesma (Ilustração 11). Apesar da suspeita de desenvolvimento de bioincrustação não tenha sido confirada, foi verificado, na inspeção de janeiro de 2020 a formação de bolhas o que foi avaliado por um inspetor qualificado contratado na parada de Angra 1 que poderia tratar-se não de uma falha do produto mas uma falha na aplicação do revestimento.

\subsubsection{Revestimento INTERSLEEK 1100 SR do fornecedor AKZO NOBEL aplicado em setembro de 2017}

INTERSLEEK 1100 SR é um revestimento fluoropolímero de desprendimento de incrustações, para controle de limo sugerido pelo fornecedor para teste na superfície do túnel de descarga. Aplicado sobre o epóxi puro de dois componentes INTERSHIELD 300, resistente a abrasão com pigmentos de alumínio que proporcionam excelente e duradoura proteção anticorrosiva. Formulado com tecnologia de polímeros, permitindo a rápida cura e repintura, mesmo em condições com baixa temperatura, apresenta os dados técnicos a seguir. Acabamento/Brilho: Brilhante; Comp. B (Agente de cura) FXA993 (Parte B), FXA994 (Parte C); Sólidos por Volume: 72\% 土2\% (ISO 3233:1998); Relação de Mistura: 9 volumes de Comp. A para 2 volumes de Comp. B para 1 volume de Comp. C; Espessura Típica de Filme: Faixa: 150 - 200 microns seco (208-278 microns molhado) podem ser especificados dependendo do uso final; Rendimento Teórico: Faixa: 4.80 - $3.60 \mathrm{~m}^{2} /$ Litro a 150 - 200 $\mu \mathrm{m}$ seco, utilizar o fator de perda apropriado; Método de Aplicação: revestimento aplicado com trincha; Ponto de fulgor: Comp. A $46^{\circ} \mathrm{C}$; Comp. B $22^{\circ} \mathrm{C}$; Comp. C $36^{\circ} \mathrm{C}$; Mistura $33^{\circ} \mathrm{C}$ 


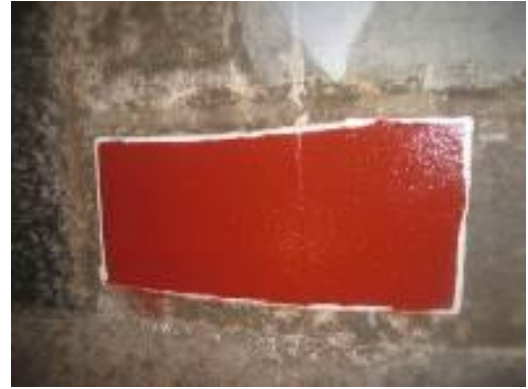

Setembro de 2017: após aplicação

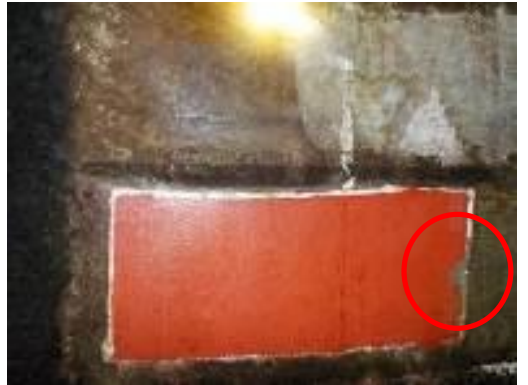

Outubro de 2018: 1 ano após aplicação

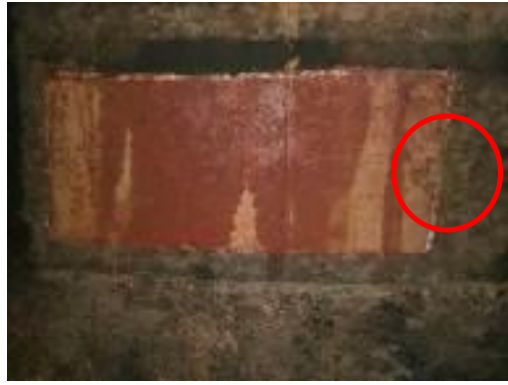

Janeiro de 2020: 2 anos e três meses após aplicação

Figura 9: Revestimento INTERSLEEK 1100 SR com biofilme e delaminação provocada pelo fluxo d’água Fonte: GOMES FILHO, S D

Quanto ao ensaio de formação de bolhas, não foi observada a ocorrência, de acordo com o padrão da norma ASTM D714-02 (Figura 9). No entanto foi verificado que o revestimento apresentou delaminação intercamadas ao longo da área pintada, salientando que a primeira camada ((INTERSHIELD 300) se manteve aderida ao subatrato.

\subsubsection{PLASTEEL ANTI CRACA do fornecedor QUIAMTIC TAPIMATIC aplicado em setembro de 2017}

PLASTEEL ANTI CRACA e um revestimento antifouling base resina epoxi curado com poliamida de alta espessura e altos sólidos. Formulado com carga oxido cuproso isento de TBT (Estanho) indicado para revestimentos de equipamentos submersos que apresenta os dados técnicos a seguir. Sólidos por volume: 99,5 +/- 1\%; Espessura recomendada: 500 - $600 \mu \mathrm{m}$ de filme seco; Rendimento teórico: $7 \mathrm{~m} 2 /$ Galão na espessura de $500 \mu \mathrm{m}$ de filme seco. Aspecto do produto: Solido rígido vitrificado; Tempo máximo para aplicação a $25{ }^{\circ} \mathrm{C}$ : 30 minutos para $5,28 \mathrm{~kg}$; Contração (ASTM D-2566): 0,0004 - 0,0006 cm; Resistência a compressão (ASTM D-695): 5,5 - 6,0 kgf/mm2; Resistência a tração (ASTM D-638): 2,3 - 2,8 kgf/mm2; Dureza Shore D (ASTM D-2240): 79 - 83; Modulo de elasticidade (ASTM D-638): 400 - $440 \mathrm{kgf} / \mathrm{mm}_{2}$; Coeficiente de expansão térmica (ASTM D-696): (40 - 46) x 10-6 cm/cm.oC; Condutividade térmica (ASTM C-177): $(1,34-1,45)$ x $10-3 \mathrm{cal} . \mathrm{cm} / \mathrm{s} . \mathrm{cm} 2 .{ }^{\circ} \mathrm{C}$; Adesão por tração (ASTM D454: 2009): Falha adesiva na cola (Y100\%) aderência superior 2000 psi; Abrasão Taber - rebolo H22, 1000 ciclos (ASTM D-4060): $\leq 0,70 \mathrm{~g}$; Resistência a temperatura Continua: $90{ }^{\circ} \mathrm{C}$, Pico: $120{ }^{\circ} \mathrm{C}$.

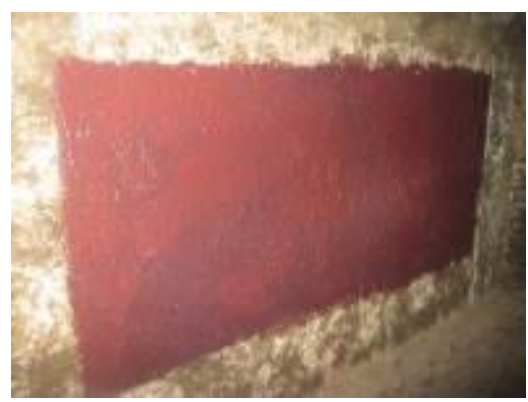

Setembro de 2017: após aplicação

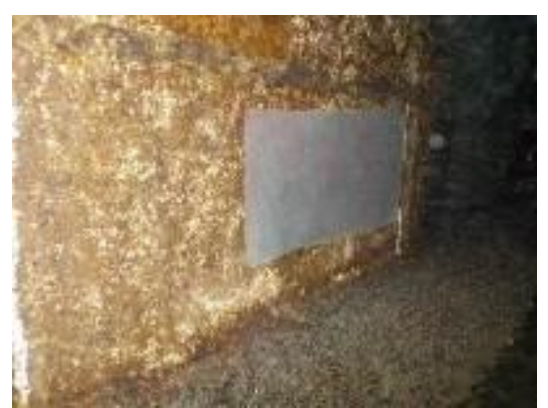

Outubro de 2018: 1 ano após aplicação

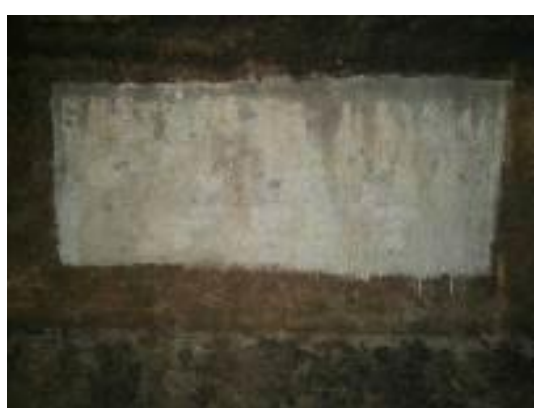

Janeiro de 2020: 2 anos e três meses após aplicação

Figura 10: Revestimento PLASTEEL ANTI CRACA com descoloração e escoamento Fonte: GOMES FILHO, S D

Quanto ao ensaio de formação de bolhas, não foi observada a ocorrência, de acordo com o padrão da norma ASTM D714-02 (Figura 10). No caso deste revestimento observou-se, já em 2017 - 1 ano após sua aplicação, que ele apresentava uma mudança de cor de vermelha para cinza ao que o fornecedor suspeita que seja devido à interação do óxido cuproso componente do revestimento com componentes da água do mar. Foi observado, ainda ecoamento do revestinento, ao que o fornecedor atribuiu à espessura aplicada. 
6.3.6 PLASTEEL CERÂMICO ALTA RESISTÊNCIA QUÍMICA do fornecedor QIMATIC TAPIMATIC aplicado em outubro de 2018

PLASTEEL ALTA RESISTÊNCIA QUÍMICA é um revestimento bi-componente, na cor cinza, que proporcionando uma película lisa, com alto brilho e com baixo atrito que apresenta as propriedades (típicas para o produto curado por 7 dias a $25{ }^{\circ} \mathrm{C}$ ) a seguir. Cor: Cinza; Aspecto do produto: Sólido rígido vitrificado; Tempo máximo para aplicação a 25 ${ }^{\circ} \mathrm{C}$ : 30 minutos para 1galão; Contração (ASTM D-2566): 0,0004-0,0006 cm; Resistência à compressão (ASTM D695): 5,5 - 6,0 kgf/mm2; Resistência à tração (ASTM D-638): 2,3-2,8 kgf/mm2; Dureza Shore D (ASTM D-2240): 79 - 83; Módulo de elasticidade (ASTM D-638): 400 - $440 \mathrm{kgf} / \mathrm{mm} 2$; Coeficiente de expansão térmica (ASTM D696): $\left(40\right.$ - 46) x 10-6 cm/cm. ${ }^{\circ} \mathrm{C}$; Condutividade térmica (ASTM C-177): $(1,34-1,45)$ x 10-3 cal.cm $/ \mathrm{s} . \mathrm{cm} 2 .{ }^{\circ} \mathrm{C}$; Adesão por tração (ASTM D454: 2009): Falha adesiva na cola (Y100\%) aderência superior 2000 psi; Abrasão Taber - rebolo H22, 1000 ciclos (ASTM D-4060): $\leq 0,70 \mathrm{~g}$; Resistência à temperatura Contínua: $90^{\circ} \mathrm{C}$, Pico: $120^{\circ} \mathrm{C}$.

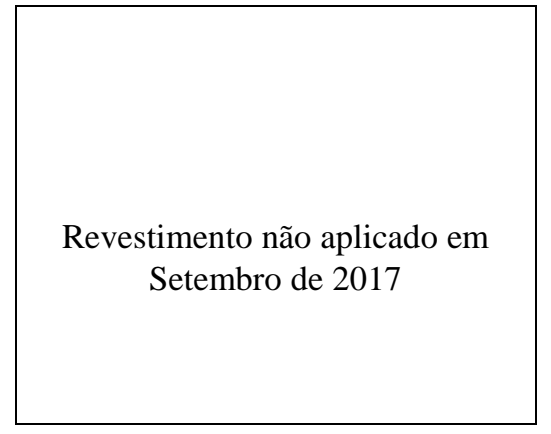

Setembro de 2017: Revestimento não aplicada

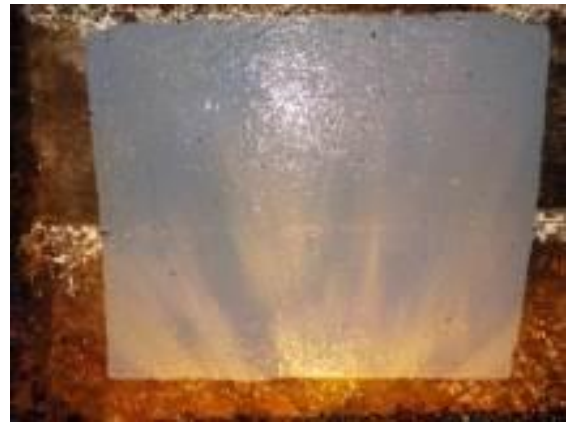

Outubro de 2018: Após aplicação

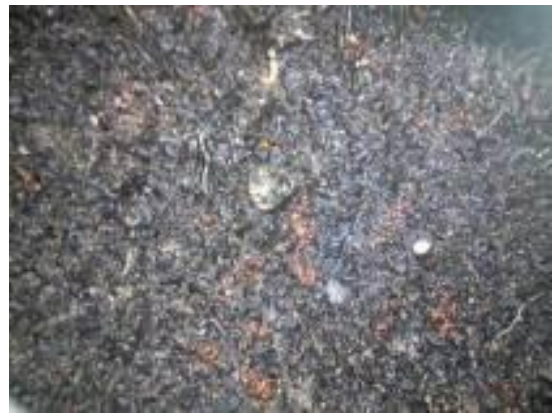

Janeiro de 2020: 1 ano e três meses após aplicação

Figura 11: Revestimento PLASTEEL ALTA RESISTÊNCIA QUÍMICA encoberto pelo molusco da bioincrustação Fonte: GOMES FILHO, S D

Não foi possível observar a formação de bolhas, de acordo com o padrão da norma ASTM D714-02 pois como descrito na avaliação do desenvolvimento da bioincrustação, o molusco predominante na região do túnel em que o revestimento foi aplicado encobriu totalmente a área em que aplicado o revestimento (Figura 11).

\section{CONCLUSÕES}

Quanto à atividade da bioincrustação foi possível verificar que a bioincrustação tanto na região das galerias, na região de transição entre o final das galerias e o início do túnel quanto no túnel de descarga está ativa o que fícou demonstrado pelo desenvolvimento da bioincrustação tanto da craca da espécie Megabalanus coccopoma com menor velocidade nas galerias quanto quando comparada `a maior velocidade no seu desenvolvimento do molusco gastrópode Petaloconchus varians da família Vermetidae na áreaa do túnel. Em resumo, verificou-se o predomínio do crescimento da craca na área das galerias cuja configuração é mais curva e o predomínio do crescimento do molusco na área do túnel cuja configuração é mais reta.

O menor desenvolvimento da craca possibilitou avaliar as proriedades físicas dos revestimentos aplicadas nas galerias donde se concluiu que os revestimentos PLASTEEL AZUL PINTÁVEL do fornecedor QUIMATIC/TAPIMATIC, ICOSIT K $101 \mathrm{TW}$ do fornecedor SIKA Brasil e PLASTEEL ANTI CRACA também do fornecedor QUIAMTIC TAPIMATIC permaneceram aderidas à superfície da parede das galerias de descarga, criando a possibilidade de proteção da estrutura de concreto pintada contra entrada de contaminantes oriundos da água do mar apesar do grau de umidade do ambiente do túnel que impossibilitou a perfeita colagem dos dolly à superfície dos revestimentos. Além disso, a remoção da bioincrustação das paredes das galerias e túnel de descarga nas seis áreas inicadas na Figura 4, possibilitou a inspeção, por amostragem, dessas estruturas de concreto armado.

Quanto aos revestimentos MC-DUR 2496 CTP do fornecedor MC-Bauchemie Brasil e INTERSLEEK 1100 SR do fornecedor AKZO NOBEL concluimos que estes revestimentos, apesar de não terem a sua eficácia anti-incrustante testada em razão da baixa velocidade de desenvolvimento da craca, eles falharam na função de criar a possibilidade de proteger a estrtutura de concreto pintada contra a entrada de contaminantres oriundos da água do mar em razão da 
formação de bolhas "densa" e delaminação, respectivamente. Quanto à eficácia anti-incrustante dos revestimentos aplicadas na região de predominância da craca, não foi observado desenvolvimento de bioincrustação sobre os revestimentos. Podemos, ainda, afirmar que o revestimento PLASTEEL ALTA RESISTÊNCIA QUÍMICA do fornecedor QUIMATIC/TAPIMATIC podemos concluir que ela não apresenta eficácia anti-incrustante visto que o molusco cobriu totalmente a área onde este revestimento foi aplicado.

Tabela 1 - Planilha com valores e anotações dos resultados encontrados

Fonte: GOMES FILHO, S D

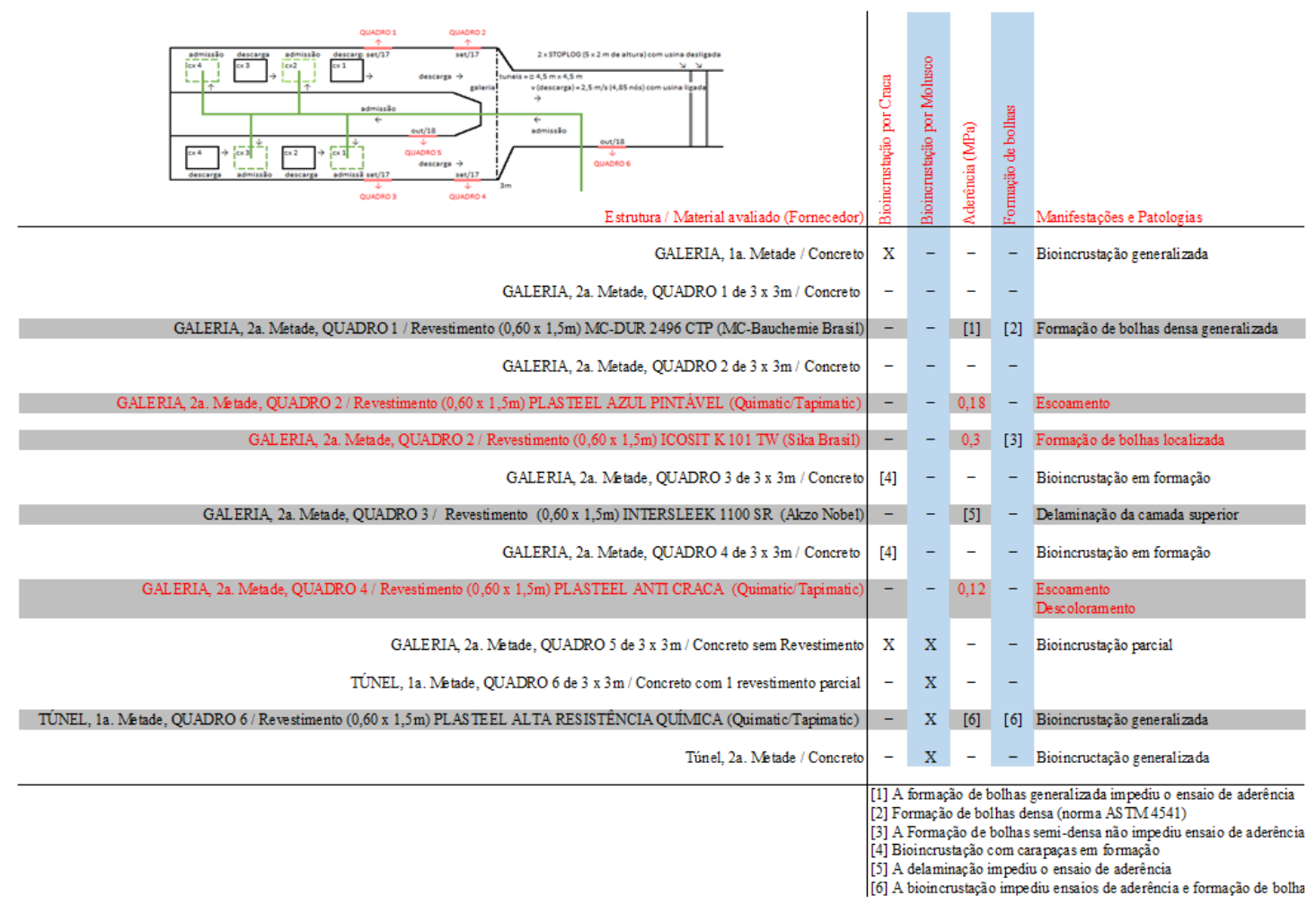

Observamos, ainda, que o revestimento PLASTEEL ANTI CRACA do fornecedor QUIMATIC / TAPIMATIC apesar de ter sofrido mudança de coloração de vermelho para cinza e apresentado alguns escoamentos, se manteve aderida á superfície interna da área reestida (Valores de aderência na Tabela 1), criando a possibilidade de proteger a estrutura contra a entrada de contaminantes da água do mar.

\section{REFERÊNCIAS}

ELETROBRÁS TERMONUCLEAR S.A. Final Safety Analysis Report - FSAR Angra 1 (ver 32). Eletronuclear, Rio de Janeiro, 2004.

LEITE, N. F. Efeitos da incrustação de macroorganismos sobre materiais de centrais nucleares que utilizam água do mar nos sistemas de refrigeração. 1999. Dissertação (Mestrado em Engenharia Metalúrgica e de Materiais) Universidade Federal do Rio de Janeiro.

GIL, Antônio Carlos. Como elaborar projetos de pesquisa. 4. ed. São Paulo: Atlas, 2002.

FREITAS, Wesley Ricardo de Sousa ; JABBOUR, Charbel José Chiappetta . Utilizando estudo de caso(s) como estratégia de pesquisa qualitativa: boas práticas e sugestões. Estudo \& Debate (UNIVATES. Impresso), v. 18, p. 7-22, 2011.

Safriel, U.N., Cohen, Y. Erez, N., Gateno, D., Keasar, T. \& Dolev, Y. 1993. Biological control of marine biofouling. Oebalia 19 (suppl.): 193-199.

HELENE, Paulo. Contribuição ao estudo da corrosão em armaduras de concreto armado. 1993. 248p. (Habilitation thesis) Escola Politécnica, Universidade de São Paulo 